• 研究报告・

\title{
不同取样强度下古田山木本植物幼苗组成 及其分布格局比较
}

\author{
郭 印 ${ }^{1,2}$ 王云泉 ${ }^{1,2}$ 陈 磊 ${ }^{*}$ 米湘成 ${ }^{2}$ 任海保 ${ }^{2}$ 陈声文 ${ }^{3}$ 陈建华 ${ }^{1^{*}}$ \\ 1 (浙江师范大学化学与生命科学学院, 浙江金华 321004) \\ 2 (中国科学院植物研究所植被与环境变化国家重点实验室, 北京 100093) \\ 3 (古田山国家级自然保护区管理局, 浙江开化 324300)
}

\begin{abstract}
摘要: 幼苗阶段是森林群落更新的瓶颈, 研究木本植物幼苗组成和分布格局对正确认识森林群落构建以及多样性 维持机制具有十分重要的意义。以往基于幼苗阶段的研究取样强度较小, 主要涉及常见种, 缺乏对稀有种的有效 监测。我们对古田山 24 ha森林样地幼苗监测网络进行了扩建, 在已有 507 个 $1 \mathrm{~m} \times 1 \mathrm{~m}$ 幼苗监测样方的基础上, 增设 了 285 个 $5 \mathrm{~m} \times 5 \mathrm{~m}$ 幼苗样方, 对样方内所有高度 $\geqslant 10 \mathrm{~cm}$ 且胸径 $<1 \mathrm{~cm}$ 的木本植物幼苗按大样地监测标准进行了 定位、挂牌、鉴定和测量。本研究利用 2012 年 $5 \mathrm{~m} \times 5 \mathrm{~m}$ 幼苗监测样方的首次调查数据, 比较了 24 ha大样地中不同 取样强度下幼苗和非幼苗(胸径 $\geqslant 1 \mathrm{~cm}$ 的木本植物)个体在物种组成、多样性分布格局以及生境偏好等方面的差 异。结果表明: (1) 285 个 $5 \mathrm{~m} \times 5 \mathrm{~m}$ 幼苗监测样方共计有木本植物幼苗138种 20,581 株, Shannon-Wiener多样性指数以 及经多度校正的物种丰富度指数均显著高于 $1 \mathrm{~m} \times 1 \mathrm{~m}$ 幼苗监测样方以及 $24 \mathrm{ha}$ 大样地的非幼苗个体, 该结果与基 于Rarefaction方法计算的物种数期望值结果一致; 与 $1 \mathrm{~m} \times 1 \mathrm{~m}$ 幼苗监测样方结果相比, $5 \mathrm{~m} \times 5 \mathrm{~m}$ 幼苗监测样方内 物种数-取样面积曲线趋于饱和。(2) $5 \mathrm{~m} \times 5 \mathrm{~m}$ 幼苗监测样方幼苗与 $24 \mathrm{ha}$ 大样地非幼苗个体物种多度呈异速增长关 系, 表明植物在幼苗阶段受到负密度制约效应的影响, 死亡率相对较高。(3)取样强度和胸径阈值的选取对群落稀 有种的界定有重要影响, 朱砂根(Ardisia crenata)、山鸡椒(Litsea cubeba)、美丽胡枝子(Lespedeza thunbergii subsp. formosa) 等物种在 24 ha样地水平被认为是稀有种, 但是在 $5 \mathrm{~m} \times 5 \mathrm{~m}$ 幼苗样方却属于常见种。(4)指示种分析结果表 明, 基于不同取样强度的幼苗生境指示种与基于大样地非幼苗个体的分析结果存在较大差异。在 $5 \mathrm{~m} \times 5 \mathrm{~m}$ 幼苗样 方中, 13 个物种与单一生境类型显著相关, 其中仅有 3 个物种与 $1 \mathrm{~m} \times 1 \mathrm{~m}$ 幼苗样方指示种相同, 与 $24 \mathrm{ha}$ 大样地非幼 苗相比, 仅有 2 个共有指示种。总之, 不同取样强度可显著影响幼苗物种多样性格局的分析结果, 通过样方扩建对 林下幼苗进行系统监测，可进一步加深对群落生物多样性维持机制的认识。
\end{abstract}

关键词: 古田山; 木本植物幼苗; 取样强度; 稀有种; 物种多样性维持机制

\section{Comparing tree seedling composition and distribution patterns under different sampling intensities in the 24 ha Gutianshan forest dynamics plot}

\footnotetext{
Yin Guo ${ }^{1,2}$, Yunquan Wang ${ }^{1,2}$, Lei Chen ${ }^{2 *}$, Xiangcheng $\mathrm{Mi}^{2}$, Haibao Ren ${ }^{2}$, Shengwen Chen ${ }^{3}$, Jianhua Chen ${ }^{1 *}$ 1 College of Chemistry and Life Sciences, Zhejiang Normal University, Jinhua, Zhejiang 321004

2 State Key Laboratory of Vegetation and Environmental Change, Institute of Botany, Chinese Academy of Sciences, Beijing 100093

3 Gutianshan National Nature Reserve Administrative Bureau, Kaihua, Zhejiang 324300
}

\begin{abstract}
As the seedling stage is the bottleneck in forest tree regeneration, knowledge of the composition and structure of seedlings is crucial to understanding the mechanisms of community assemblage and diversity maintenance. However, based on the limited sampling intensity common in previous studies, seedling census datasets are representative of common species, but are ineffective for monitoring rare species. In this
\end{abstract}

收稿日期: 2015-12-03; 接受日期: 2016-10-19

基金项目: 国家自然科学基金面上项目(31270495)

*共同通讯作者:Co-authors for correspondence. E-mail: sky78@zjnu.cn; chenlei@ibcas.ac.cn 
study, we established a new seedling monitoring network in the 24 ha Gutianshan (GTS) forest dynamics plot (FDP) consisting of 285 seedling plots $(5 \mathrm{~m} \times 5 \mathrm{~m})$ in 2012. In the seedling pots, all woody plants (DBH $<1 \mathrm{~cm}$ and height $\geqslant 10 \mathrm{~cm}$ ) were tagged, mapped and measured every two years. We used the first census data to investigate seedling composition, species diversity patterns, seedling, and non-seedling species habitat association. Our results showed that: (1) There were 138 species, consisting of a total of 20,581 individuals in 285 seedling plots of $5 \mathrm{~m} \times 5 \mathrm{~m}$. The Shannon-Wiener diversity index and Rarefied species richness were higher than those of the $1 \mathrm{~m} \times 1 \mathrm{~m}$ seedling plots and 24 ha FDP census (DBH $\geqslant 1 \mathrm{~cm}$ ). Similar results were found when using rarefaction approach. Compared with $1 \mathrm{~m} \times 1 \mathrm{~m}$ seedling plots, the number of species showed a significant increase and the species-area curve became more asymptotic. (2) The relationship between seedling abundance and tree species exhibited negative allometry, suggesting that the mortality rate of plants in the seedling stage was relatively high compared with the rate found in the non-seedling stage due to the negative density dependence. (3) Sampling intensity and selection of DBH cutoffs influence the definition of rare species. Some rare species defined by trees with $\mathrm{DBH} \geqslant 1 \mathrm{~cm}$ were not actually rare when individuals with $\mathrm{DBH}<1 \mathrm{~cm}$ were considered (i.e. Ardisia crenata, Litsea cubeba, Lespedeza thunbergii subsp. for$m o s a$ ). (4) The indicator species of the $5 \mathrm{~m} \times 5 \mathrm{~m}$ seedling plots were different from those found in the 24 ha FDP and the $1 \mathrm{~m} \times 1 \mathrm{~m}$ seedling census. 13 species was significantly correlated with single habitat type in these $5 \mathrm{~m} \times 5 \mathrm{~m}$ seedling plots, which shared only three species that identified as indicator species for $1 \mathrm{~m} \times$ $1 \mathrm{~m}$ seedling plots and two species for non-seedling plots. In conclusion, sampling intensity influenced patterns of tree seedling composition and community diversity, and increasing sampling intensity can provide deeper insights into the processes of diversity maintenance.

Key words: Gutianshan (GTS); tree seedling; sampling intensity; rare species; mechanisms of maintenance of species diversity

林下幼苗是森林生态系统的重要组成部分 (Parent et al, 2003), 也是森林群落更新的关键, 其 动态变化将会直接影响群落的物种组成和空间结 构(Green et al, 2014)。热带和亚热带森林的相关研 究表明, 很多生态学过程如负密度制约和生境过滤 都会对幼苗动态产生影响, 并会延续到其后的多个 生活史阶段(Szwagrzyk et al, 2001; Lambers et al, 2002; Paine \& Harms, 2009)。因此, 研究森林中的幼 苗更新格局和动态有助于揭示群落构建过程以及 生物多样性维持机制(Hubbell et al, 1998; Antos et al, 2005)。

亚热带常绿阔叶林是我国的特色植被之一, 也 是我国生物多样性最为丰富的地带性植被(吴征镒, 1980; 宋永昌等, 2005)。目前, 关于亚热带森林物种 组成和群落结构的研究已获得广泛关注(祝燕等, 2008; 杨庆松等, 2011; 金毅等, 2015)。但是以往基 于大样地的研究主要侧重于探讨胸径 $(\mathrm{DBH}) \geqslant 1$ $\mathrm{cm}$ 的非幼苗的多样性格局, 对林下幼苗的研究较 少, 即使有一些研究涉及幼苗, 也由于取样强度较 小, 并不能充分反映群落水平的幼苗组成和分布格 局(Chen et al, 2010; Bin et al, 2012)。同时, 森林群落
中很多物种是稀有种，由于扩散限制、生境过滤等 因素的影响，这些物种往往呈聚集分布，不充分的 取样容易低估它们在群落水平的贡献(McGill et al, 2006; Mi et al, 2012)。

正确认识群落物种组成及其分布格局是揭示 群落多样性维持机制的关键。不同生态学过程通常 能够通过影响森林群落幼苗的更新、生长以及死亡, 最终改变群落生物多样性的空间分布格局(Paine et al, 2012; Muscarella et al, 2013)。例如，扩散限制导 致种子散布在母树附近, 形成物种的聚集分布格局 (Svenning \& Wright, 2005); 由于资源竞争和共享病 原菌, 局域较大的同种个体密度会导致幼苗死亡率 上升，产生负密度制约效应(Janzen，1970；Connell， 1971); 由于物种对环境偏好的差别, 生境异质性能 够通过生境过滤显著改变物种的分布(Wang et al, 2011)。树木的生活史周期一般会持续几十年甚至上 百年, 不同生态学过程会共同作用于其生活史的各 个阶段, 并留下可被检测的信号(Lebrija-Trejos et al, 2010; Jansen et al, 2014)。木本植物幼苗阶段是森 林更新重要的生活史阶段之一, 揭示其动态格局对 认识森林群落的多样性维持具有十分重要的意义 
(Goldsmith et al, 2006)。因此, 通过物种分布格局推 测其背后潜在的生态学过程成为现代群落生态学 研究的重要手段, 而建立完善的森林动态监测网络 正日益成为研究群落多样性维持机制的关键 (Carson et al, 2008)。近年来, 随着世界范围内大型 森林动态样地的建立, 利用群落物种组成和多样性 格局探讨森林物种共存机制成为当下群落生态学 研究的热点之一(宋永昌等, 2015)。

我们通过对古田山 $24 \mathrm{ha}$ 森林动态监测样地中 幼苗监测样方的扩建, 增设了 285 个 $5 \mathrm{~m} \times 5 \mathrm{~m}$ 幼苗 监测样方, 对样方内所有高度 $\geqslant 10 \mathrm{~cm}$ 且DBH $<1$ $\mathrm{cm}$ 的木本植物幼苗进行监测, 并于 2012 年完成了 首次调查。我们以该数据为基础, 结合样地内已经 开展的种子雨和调落物监测, 初步实现了对样地内 木本植物多个生活史阶段(种子、幼苗、小树以及大 树)的动态监测, 为从不同生活史阶段探究多样性 的形成和维持机制提供了可能。本研究通过比较不 同取样强度下样地内幼苗及非幼苗个体在物种组 成、多样性分布格局以及生境偏好等方面的差异, 主要探讨样地幼苗和非幼苗阶段的物种组成及多 样性分布格局、稀有种组成的差异, 以及植物的这 两个阶段对生境异质性的不同响应。

\section{1 材料与方法}

\section{1 研究区概况}

古田山国家级自然保护区位于浙江开化县, 总 面积 $8,107 \mathrm{ha}$, 主峰青尖海拔 $1,258 \mathrm{~m}$, 属中亚热带 常绿阔叶林区域。古田山地处亚热带季风气候区, 年均降水量 $1,963.7 \mathrm{~mm}$, 年平均气温 $15.3^{\circ} \mathrm{C}$, 主要 土壤类型为红壤、黄红壤、红黄壤和沼泽土, 呈酸 性(胡正华等, 2003)。保护区有野生种子植物149科 648属1,426种(包括种以下分类单位), 其中国家级 珍稀濒危植物 17种, 而香果树 (Emmenopterys henryi)、野含笑(Michelia skinneriana)和紫茎(Stewartia sinensis) 3种珍稀植物的群落之大, 分布之集中为 全国罕见(楼炉焕和金水虎, 2000)。

古田山 24 ha森林动态监测样地 $\left(29^{\circ} 15.102^{\prime}-\right.$ $29^{\circ} 15.344^{\prime} \mathrm{N}, 118^{\circ} 07.010^{\prime}-118^{\circ} 07.400^{\prime}$ E) 始建于 2004年11月。样地东西长 $600 \mathrm{~m}$, 南北宽 $400 \mathrm{~m}$, 地 形极为复杂, 最大海拔高差 $268.6 \mathrm{~m}$ 。参照 CTFS (Center for Tropical Forest Science)样地建设标准, 对样地内所有 $\mathrm{DBH} \geqslant 1 \mathrm{~cm}$ 的木本植物进行定位、
挂牌, 记录其树种名称、DBH、坐标等(Condit, 1998)。2005年首次调查共记录到木本植物 159 种 140,700 株, 分属于 49 科 104属。甜槠(Castanopsis eyrei)、木荷(Schima superba)和马尾松(Pinus massoniana) 为主要优势种。样地内垂直结构清晰, 由林 冠层、亚乔木层和灌木层组成(祝燕等, 2008)。

\section{2 方法}

\subsection{1 幼苗监测样方设置与调查}

在古田山 24 ha森林动态监测样地已有的507个 $1 \mathrm{~m} \times 1 \mathrm{~m}$ 幼苗监测样方的基础上(田锴等, 2013), 于2011年按照“规则取样法”在样地内均匀增设了 285 个 $5 \mathrm{~m} \times 5 \mathrm{~m}$ 幼苗监测样方, 每个样方位于所在 $20 \mathrm{~m} \times 20 \mathrm{~m}$ 样方的东北角, 距离样方北边界和东边 界各 $2 \mathrm{~m}$ (图1)。

对 285 个 $5 \mathrm{~m} \times 5 \mathrm{~m}$ 幼苗监测样方内所有高度 $\geqslant 10 \mathrm{~cm}$ 且 $\mathrm{DBH}<1 \mathrm{~cm}$ 的木本植物幼苗进行定位、 挂牌, 记录相关物种名、植株高度、叶片数、根萌 数等。于 2012 年 5 月完成第一次调查, 以后每两年复 查一次, 本研究主要基于首次调查数据。

\subsection{2 数据分析方法}

(1)木本植物幼苗重要值的计算公式为: 重要 值 $=$ 相对多度 + 相对频度(陈章和等, 1996), 其 中相对多度 $=($ 目标种的多度/所有种的多度和 $) \times$ $100 \%$, 相对频度 $=($ 目标种的频度/所有种的频度 和) $\times 100 \%$ 。

(2)种一面积曲线的计算采用Kindt's exact积累 计算方法(Ugland \& Ellingsen, 2003)。

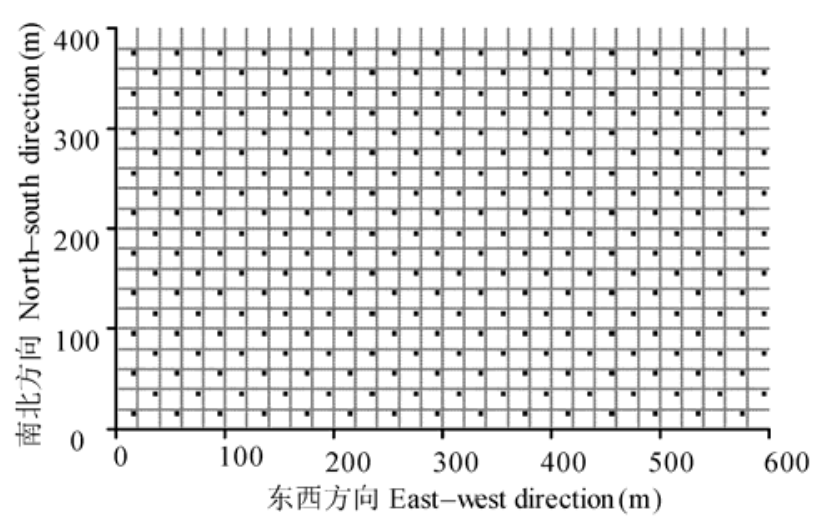

图1 古田山 24 ha森林动态监测样地中 285 个 $5 \mathrm{~m} \times 5 \mathrm{~m}$ 幼苗 监测样方分布图

Fig. 1 The layout of 285 seedling plots $(5 \mathrm{~m} \times 5 \mathrm{~m})$ in the 24 ha GTS forest dynamics plot 


$$
\begin{aligned}
& S_{\mathrm{n}}=\sum_{i=1}^{S}\left(1-p_{\mathrm{i}}\right) \\
& p_{\mathrm{i}}=\left(\begin{array}{c}
N-f_{\mathrm{i}} \\
n
\end{array}\right) /\left(\begin{array}{l}
N \\
n
\end{array}\right)
\end{aligned}
$$

其中, $f \mathrm{i}$ 是物种 $i$ 的频度, $\left(\begin{array}{l}N \\ n\end{array}\right)$ 为二项式系数, $S$ 为群落 中物种数, $S_{\mathrm{n}}$ 为随着面积增加累计的物种数, $p_{\mathrm{i}}$ 为物 种 $i$ 的频度校正值。

(3)树种幼苗多样性采用Shannon-Wiener多样性 指数 $(H)$ 和Pielou均匀度指数 $(E)$ 衡量(Shannon, 1948; Pielou, 1975):

$$
\begin{aligned}
& H=-\sum_{i=1}^{S} P_{\mathrm{i}} \ln P_{\mathrm{i}} \\
& E=\frac{H}{\ln S}
\end{aligned}
$$

其中, $P_{\mathrm{i}}=N_{\mathrm{i}} / N_{0}, N_{0}$ 为观察到的物种总个体数, $N_{\mathrm{i}}$ 为 物种 $i$ 的个体数, $S$ 为群落中物种数。

(4)幼苗与 24 ha大样地内非幼苗 $(\mathrm{DBH} \geqslant 1$ $\mathrm{cm}$ )物种多度关系采用Comita等(2007)提出的计算 方法, 公式如下:

$\log N=\log a+b \times \log R$

其中, $N$ 为 $5 \mathrm{~m} \times 5 \mathrm{~m}$ 幼苗监测样方内幼苗物种多度, $R$ 为 24 ha样地内非幼苗物种多度, $a$ 为幼苗的平均密 度, $b$ 为斜率 $(95 \%$ 置信区间)。如果 $b<1$ 或 $b>1$, 则不 同物种幼苗与非幼苗多度呈异速增长关系。

(5) Rarefaction抽样采用Hurlbert (1971)和Heck 等(1975)的公式计算:

$$
E\left(S_{n}\right)=S-\left(C_{N}^{n}\right)^{-1} \sum_{i=1}^{S} C_{N-N_{i}}^{n}
$$

其中, $E\left(S_{n}\right)$ 为随机抽取 $5 \mathrm{~m} \times 5 \mathrm{~m}$ 幼苗监测样方中 1,000 个个体的物种数期望值, $N$ 为群落中物种个体 总数, $S$ 为群落中物种数, $N_{\mathrm{i}}$ 为物种 $i$ 的个体数, $n$ 为抽 取样本中所包含的个体数(本文中 $n=1,000$ )。

(6)参照多元回归树(multivariate regression tree, MRT)的划分结果(Legendre et al, 2009), 古田山24 ha森林动态监测样地可划分为 5 种生境类型: 低地 山谷、低地山脊、中位山坡、高位山坡和高地山脊, 其中高位山坡生境类型仅占总面积的 $1.33 \%$ 。所设 5 $\mathrm{m} \times 5 \mathrm{~m}$ 幼苗监测样方涵盖除高位山坡之外的所有 生境类型。生境指示种用指示值和表示关联程度大 小的物种-生境关联度 $\left(r_{\mathrm{pb}}\right)$ 表示, 根据 Dufrêne和 Legendre (1997)、de Cácere和Legendre (2009)及de Cáceres等(2010)改进的指示种分析方法, 以不同生 境组合为单元, 计算不同物种在不同生境单元中经 过等价权重平衡后的指示值(IndVal.g)。计算公式
如下:

$$
\begin{aligned}
& \text { IndVal.g }=\text { A. } g \times B=\frac{\frac{N}{k} \sum_{i \in c} \frac{a_{i}}{N_{i}}}{\frac{N}{k} \sum_{i \in K} \frac{a_{i}}{N_{i}}} \times \frac{\sum_{i \in C} n_{\mathrm{i}}}{\sum_{i \in C} N_{\mathrm{i}}} \\
& r_{p b}=\sqrt{\text { IndVal.g }}
\end{aligned}
$$

其中, $N$ 为幼苗样方数, $N_{\mathrm{i}}$ 为属于生境类型 $i(i=1,2$, $3,4,5)$ 的样方数, $n$ 为目标物种出现的样方数, $n_{\mathrm{i}}$ 为 其在生境类型 $i$ 中出现的样方数, $a$ 为目标种的多度, $a_{\mathrm{i}}$ 为生境类型 $i$ 中的多度, $K$ 为所有属于生境类型 $k$ 的 样方数, $C$ 为属于某一特定的生境类型组合 $C$ 的样方 集合。指示值可以分为两个部分: $A . g$ 预测某物种可 以作为某种生境组合的指示种的能力(正相关程度), $B$ 代表该目标物种在该生境中出现的频度。

本研究中所有数据统计分析和制图均在R 3.1.3 中进行, 所用的软件包主要有vegan (Oksanen et al, 2013)、doBy、spaa、permute、indicspecies 等(de Cáceres et al, 2010)。

\section{2 结果}

\section{1 物种组成}

在 285 个 $5 \mathrm{~m} \times 5 \mathrm{~m}$ 幼苗监测样方的首次调查中 共记录到木本植物幼苗 138 种 20,581 株, 分属于 44 科 95属。其中常绿树种 73 种, 占总物种数的 $52.89 \%$, 总 重要值的 $71.08 \%$ 。不同物种幼苗个体数差异较大(表 1; 附录1)。甜槠的个体数最多并且分布广泛，占总个 体数的 $19.97 \%$, 出现在 $96.69 \%$ 的样方中; 拟赤杨 (Alniphyllum fortunei)共计 1,448 株, 分布于 157 个样方 中, 分别占总样方数和总个体数的 $57.72 \%$ 和 $7.03 \%$ 。

随着取样面积的不断扩大, $5 \mathrm{~m} \times 5 \mathrm{~m}$ 幼苗监测 样方的种一面积曲线在取样面积达到 $0.40 \mathrm{ha}$ (占总 面积的 $56.14 \%$ )时，包括了 131 个物种(占 $5 \mathrm{~m} \times 5 \mathrm{~m}$ 幼苗样方总物种数的 $95 \%$ ), 样方总面积达到 $0.71 \mathrm{ha}$ 时, 曲线趋于平衡(图2)。由于 $1 \mathrm{~m} \times 1 \mathrm{~m}$ 幼苗样方取 样总面积仅有 0.05 ha (占 $5 \mathrm{~m} \times 5 \mathrm{~m}$ 样方总面积的 $7.11 \%$ ), 其种-面积曲线未能达到平衡状态(图2)。

\section{2 多样性分布格局}

参照李立等(2010)对古田山乔冠层物种径级结 构的划分标准, 将 24 ha样地内非幼苗个体按DBH 划分为 4 个等级, 并分别计算了不同取样强度下幼 苗以及不同径级非幼苗个体的物种多样性指数(表 2)。从幼苗到大树, 物种多样性总体呈现先高后低 的趋势, 其中 $5 \mathrm{~m} \times 5 \mathrm{~m}$ 取样强度下幼苗整体的 
表1 古田山 $5 \mathrm{~m} \times 5 \mathrm{~m}$ 幼苗监测样方主要物种重要值 $(I V)$ 等基础信息

Table 1 The basic information of main species such as importance value (IV) in GTS $5 \mathrm{~m} \times 5 \mathrm{~m}$ seedling plots

\begin{tabular}{|c|c|c|c|c|}
\hline 物种名 Species & 科名 Family & 个体数 No. of individuals & 重要值 $I V(\%)$ & 生活型 Life form \\
\hline $\begin{array}{l}\text { 甜槠 Castanopsis eyrei } \\
\end{array}$ & 壳斗科 Fagaceae & 4,110 & 24.85 & 常绿 Evergreen \\
\hline 拟赤杨 Alniphyllum fortunei & 安息香科 Styracaceae & 1,448 & 9.95 & 落叶 Deciduous \\
\hline 虎皮楠 Daphniphyllum pentandrum & 虎皮楠科 Daphniphyllaceae & 949 & 7.67 & 常绿 Evergreen \\
\hline 赤楠 Syzygium buxifolium & 桃金娘科 Myrtaceae & 900 & 7.51 & 常绿 Evergreen \\
\hline 浙江新木姜子 Neolitsea aurata var. chekiangensis & 樟科 Lauraceae & 791 & 7.39 & 常绿 Evergreen \\
\hline 浙江红花油茶 Camellia chekiangoleosa & 山茶科 Theaceae & 783 & 7.25 & 常绿 Evergreen \\
\hline 柳叶蜡梅 Chimonanthus nitens & 蜡梅科 Calycanthaceae & 688 & 6.74 & 落叶 Deciduous \\
\hline 隔药柃 Eurya muricata & 山茶科 Theaceae & 625 & 6.04 & 常绿 Evergreen \\
\hline 毛花连荵茶 Camellia fraterna & 山茶科 Theaceae & 536 & 5.31 & 常绿 Evergreen \\
\hline 矩形叶鼠刺 Itea omeiensis & 虎耳草科 Saxifragaceae & 583 & 4.80 & 常绿 Evergreen \\
\hline 石斑木 Rhaphiolepis indica & 蓄微科 Rosaceae & 434 & 4.78 & 常绿 Evergreen \\
\hline 木荷 Schima superba & 山茶科 Theaceae & 545 & 4.76 & 常绿 Evergreen \\
\hline 马银花 Rhododendron ovatum & 杜鹃花科 Ericaceae & 428 & 4.47 & 常绿 Evergreen \\
\hline 杨梅叶蚊母树 Distylium myricoides & 金缕梅科 Hamamelidaceae & 627 & 4.42 & 常绿 Evergreen \\
\hline 红楠 Machilus thunbergii & 樟科 Lauraceae & 293 & 3.93 & 常绿 Evergreen \\
\hline 总计 Total & - & 20,581 & 200.00 & - \\
\hline
\end{tabular}

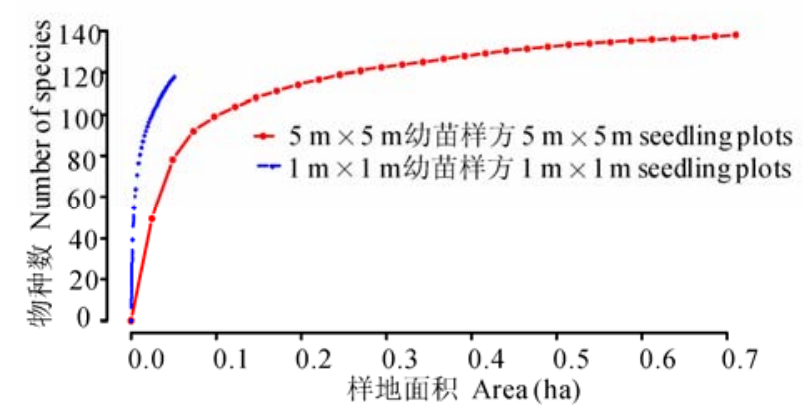

图2 古田山24 ha森林动态监测样地不同取样强度下幼苗 的种一面积曲线

Fig. 2 Species-area relationship of seedlings under different sampling intensities in the 24 ha GTS forest dynamics plot

Shannon-Wiener多样性指数高达 4.25 , 高于 $1 \mathrm{~m} \times 1$ $\mathrm{m}$ 取样强度下的幼苗多样性(4.03), 也显著高于 24 ha大样地不同阶段(幼树到大树)群落的物种多样性 (4.11-2.63, $P<0.05)$, 这与通过Rarefaction抽取各 个径级层次 1,000 个个体预估的多样性以及物种数 的总体趋势一致(表2)。此外, 生活史各阶段的 Pielou均匀度指数没有显著差别。

$5 \mathrm{~m} \times 5 \mathrm{~m}$ 取样强度下, 同一物种的幼苗多度随 着非幼苗物种多度的增加而显著增加 $(r=0.63, P<$ 0.001 , 图 3), 但是斜率远小于 $1(b=0.49, P<$ 0.001), 表明样地内幼苗与非幼苗物种多度呈异速
增长关系, 幼苗个体增速小于非幼苗个体。和非幼 苗阶段相比, 植物在幼苗阶段相对比较脆弱, 容易 受到同种密度制约、生境过滤等生态过程的影响, 死亡率相对较高。

\section{3 稀有种确定}

古田山 24 ha样地中存在大量稀有种, 个体数 少于 24 株的物种有 59 种, 占总物种数的 $37.1 \%$ (祝燕 等, 2008)。5 m $\times 5$ m幼苗监测样方调查结果表明, 大样地水平(非幼苗阶段)的稀有种在幼苗阶段并非 绝对稀有 (图4), 山鸡椒 (Litsea cubeba)、朱砂根 (Ardisia crenata)、美丽胡枝子(Lespedeza thunbergii subsp. formosa)、乳源木莲(Manglietia yuyuanensi)、 臭辣树 (Euodia fargesii)、南酸㫫(Choerospondias axiliaris)、掌叶覆盆子(Rubus chingii)、红紫珠 (Callicarpa rubella) 等8个物种在非幼苗阶段属于稀 有种, 但在幼苗阶段属于常见种。例如, 朱砂根在 24 ha大样地中的非幼苗个体仅有2株, 在幼苗中共 有 253 株且分布广泛 (占总样方的 $40.00 \%$ ); 山鸡椒 在大样地中的非幼苗个体共 17 株, 在幼苗中有 296 株且同样分布广泛(占总样方数的 $39.60 \%$ )。

\section{4 生境类型及指示种分析}

$5 \mathrm{~m} \times 5 \mathrm{~m}$ 幼苗监测样方主要生境类型是低地 山谷和低地山脊(表3), 这两种生境占幼苗样方总面 
表2 古田山 $24 \mathrm{ha}$ 森林监测样地中幼苗与非幼苗的物种多样性比较

Table 2 Comparison of species diversity of seedling and non-seedling plots in the 24 ha GTS forest dynamics plot

\begin{tabular}{|c|c|c|c|c|c|}
\hline $\begin{array}{l}\text { 类型 } \\
\text { Type }\end{array}$ & $\begin{array}{l}\text { 物种数 } \\
\text { No. of species }\end{array}$ & $\begin{array}{l}\text { 个体数 } \\
\text { No. of individuals }\end{array}$ & $\begin{array}{l}\text { Shannon-Wiener指数 } \\
\text { Shannon-Wiener index }\end{array}$ & $\begin{array}{l}\text { 抽样 } \\
\text { Rarefraction }(N=1,000)\end{array}$ & $\begin{array}{l}\text { Pielou均匀度指数 } \\
\text { Pielou evenness index }\end{array}$ \\
\hline $\begin{array}{l}\text { 幼苗样方 seedling plots } \\
1 \mathrm{~m} \times 1 \mathrm{~m} \text { 幼苗样方 } \\
1 \mathrm{~m} \times 1 \mathrm{~m} \text { seedling plots }\end{array}$ & 118 & 4,718 & 4.03 & 84.87 & 0.53 \\
\hline $\begin{array}{l}5 \mathrm{~m} \times 5 \mathrm{~m} \text { 幼苗样方 } \\
5 \mathrm{~m} \times 5 \mathrm{~m} \text { seedling plots } \\
\text { 非幼苗样方 Non-seedling } \\
\text { plots }\end{array}$ & 138 & 20,581 & 4.25 & 89.22 & 0.49 \\
\hline $1 \mathrm{~cm} \leqslant \mathrm{DBH}<2.5 \mathrm{~cm}$ & 144 & 70,916 & 4.11 & 71.83 & 0.42 \\
\hline $2.5 \mathrm{~cm} \leqslant \mathrm{DBH}<7.5 \mathrm{~cm}$ & 132 & 45,524 & 4.05 & 72.23 & 0.43 \\
\hline $7.5 \mathrm{~cm} \leqslant \mathrm{DBH}<22.5 \mathrm{~cm}$ & 115 & 17,835 & 3.81 & 66.70 & 0.42 \\
\hline $\mathrm{DBH} \geqslant 22.5 \mathrm{~cm}$ & 63 & 6,425 & 2.63 & 35.65 & 0.33 \\
\hline
\end{tabular}

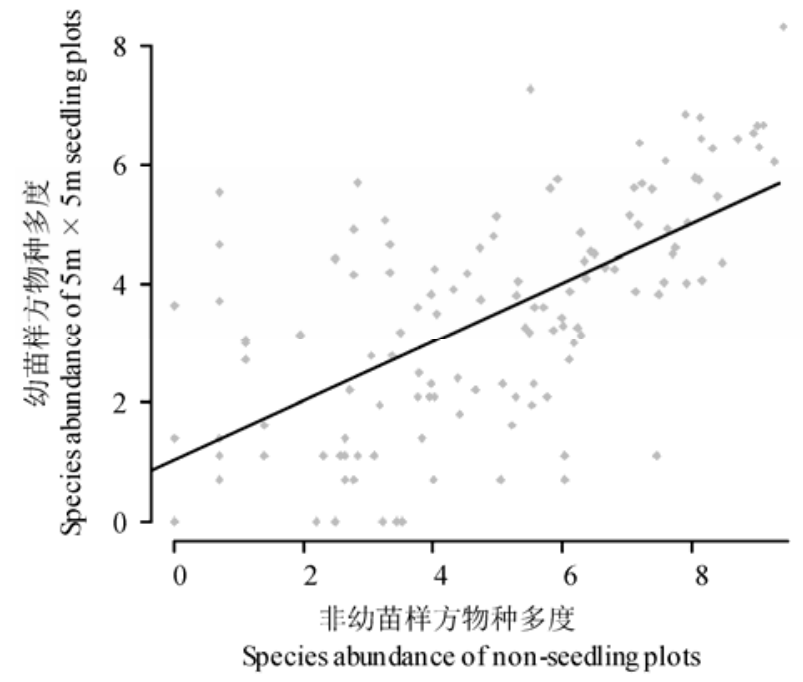

图3 古田山 24 ha森林样地 $5 \mathrm{~m} \times 5$ m幼苗样方与非幼苗样 方的物种多度对比图

Fig. 3 Comparison between the abundance of $5 \mathrm{~m} \times 5 \mathrm{~m}$ seedling plots and non-seedling plots in the 24 ha GTS forest dynamics plot

积的 $87.36 \%$ 。 $\mathrm{m} \times 5 \mathrm{~m}$ 取样强度下幼苗的物种多样 性空间分布不均匀, 沟谷地带的物种多样性较高, 每样方的Shannon-Wiener多样性指数达 $2.65 \pm 0.03$ 。 山脊地带的多样性较低, 其中低地山脊和高地山脊 每样方的Shannon-Wiener多样性指数分别为 $2.05 \pm$ 0.05 和 $1.96 \pm 0.09$ 。物种丰富度表现出与多样性不一 致的格局, 幼苗物种数较高的样方主要集中在中位 山坡生境中, 每样方中的物种数达 $24.71 \pm 2.06$ 种, 拥有的幼苗数量达 $95.92 \pm 16.77$ 棵, 这两项指数都 要高于其余3类生境(表3)。

指示种分析结果表明, 在 $5 \mathrm{~m} \times 5 \mathrm{~m}$ 幼苗监测样
方中有 13 个物种 (占总物种数的 $9.42 \%$ )与单一的生 境类型密切相关, 可以作为某一生境类型的指示 种: 其中低地山谷生境指示种最多(6种), 其次是中 位山坡(4种)和高地山脊(3种), 而低地山脊没有明 显的指示种(表4)。

\section{3 讨论}

\section{1 取样强度对种一面积曲线以及物种多样性指数 的影响}

不同取样强度可能会对群落组成和多样性格 局等造成影响(Dungan et al, 2002; Chen et al, 2013)。 在以往有关森林幼苗阶段的生态学分析中, 多以种 子雨收集器周围 $1 \mathrm{~m} \times 1 \mathrm{~m}$ 幼苗监测样方为研究对 象, 在较大取样尺度上的幼苗研究相对较少(Bai et al, 2012; Lin et al, 2012)。本研究通过样方扩建, 将 已有的幼苗监测样方从 $507 \mathrm{~m}^{2}$ 增加至 $7,125 \mathrm{~m}^{2}$, 初 步构建了覆盖古田山 $24 \mathrm{ha}$ 森林动态监测样地的林 下幼苗监测网络。通过比较 $5 \mathrm{~m} \times 5 \mathrm{~m}$ 以及 $1 \mathrm{~m} \times 1 \mathrm{~m}$ 幼苗监测样方的种一面积曲线以及多样性水平, 发 现随着取样面积的增加, 样方群落中生境异质性增 加, 物种数先迅速增加后逐渐趋于稳定, 取样面积 0.71 ha能够较好地代表古田山常绿阔叶林木本植 物幼苗的物种组成和多样性, $5 \mathrm{~m} \times 5 \mathrm{~m}$ 幼苗监测样 方中的物种多样性显著高于 $1 \mathrm{~m} \times 1 \mathrm{~m}$ 幼苗监测样 方(表2)。与生境异质性较小的样地如BCI (Comita et al 2007)及长白山样地相比较(Bai et al, 2012), 古田 山样地由于地形复杂, 海拔高差较大, 较大的幼苗 取样强度才能包括更多的生境异质性, 更好地代表 其林下木本植物幼苗的物种组成以及群落多样性 


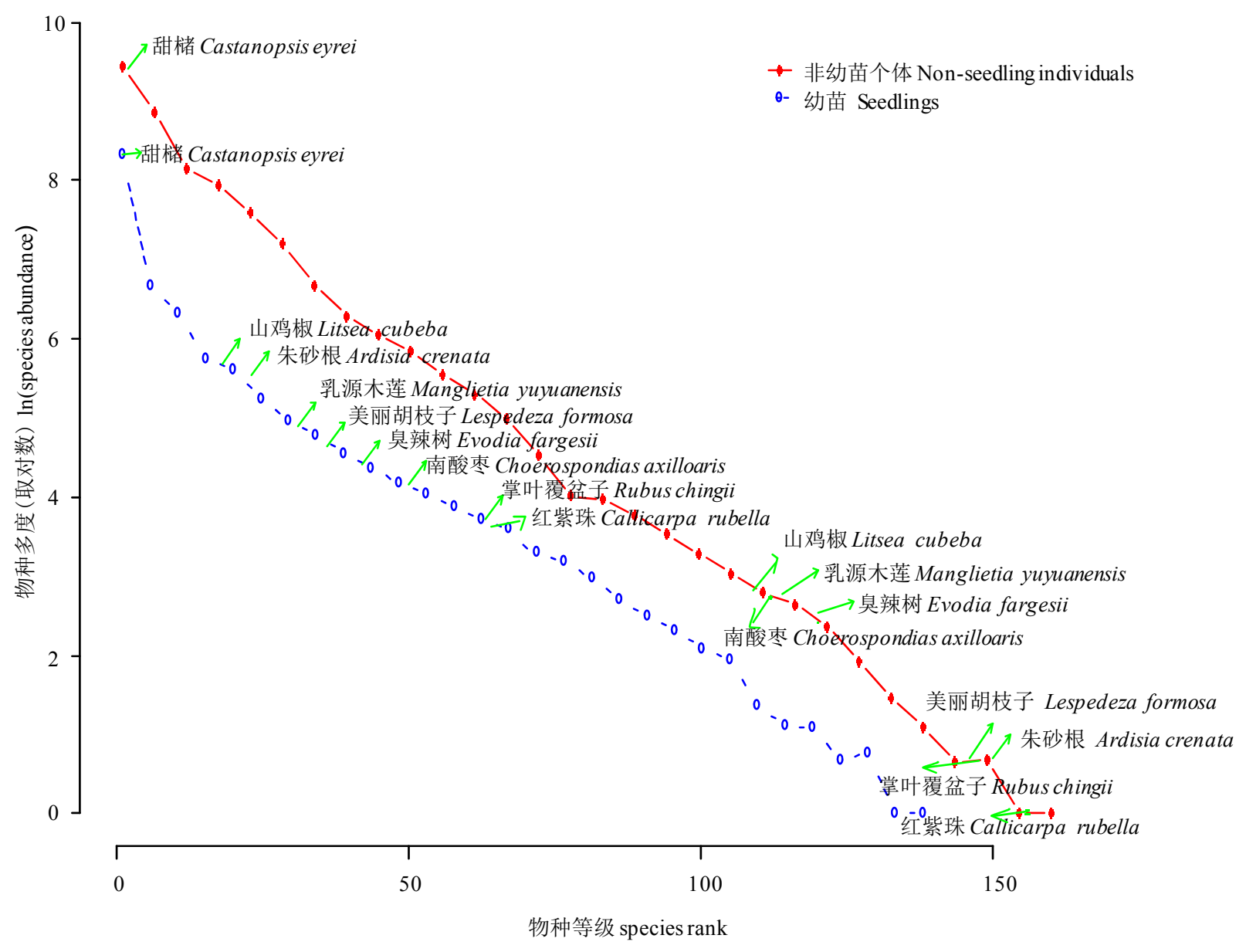

图4 古田山 24 ha森林动态监测样地 $5 \mathrm{~m} \times 5 \mathrm{~m}$ 幼苗与非幼苗样方物种等级关系图

Fig. 4 Relationship of species rank between $5 \mathrm{~m} \times 5 \mathrm{~m}$ seedling plots and non-seedling plots in the 24 ha GTS forest dynamics plot

表3 古田山 $5 \mathbf{m} \times \mathbf{5}$ m幼苗样方不同生境内物种丰富度和多样性

Table 3 Richness and species diversity of seedlings in different habitat types in GTS $5 \mathrm{~m} \times 5 \mathrm{~m}$ seedling plots

\begin{tabular}{llllll}
\hline & $\begin{array}{l}\text { 低地山谷 } \\
\text { Low valley }\end{array}$ & $\begin{array}{l}\text { 低地山脊 } \\
\text { Low ridge }\end{array}$ & $\begin{array}{l}\text { 中位山坡 } \\
\text { Middle slope }\end{array}$ & $\begin{array}{l}\text { 高地山脊 } \\
\text { High ridge }\end{array}$ & $\begin{array}{l}\text { 整个样地 } \\
\text { All types }\end{array}$ \\
\hline 样方数 No. of plots & 127 & 122 & 14 & 22 & 285 \\
幼苗数/样方数 No. of seedlings/No. of plots & $83.74 \pm 11.80$ & $61.21 \pm 9.69$ & $95.92 \pm 16.77$ & $51.54 \pm 8.03$ & $72.21 \pm 9.28$ \\
物种数/样方数 No. of species/No. of plots & $22.22 \pm 0.76$ & $15.77 \pm 0.73$ & $24.71 \pm 2.06$ & $13.54 \pm 1.04$ & $18.92 \pm 0.54$ \\
Shannon-Wiener指数/样方数 Shannon-Wiener index/ & $2.65 \pm 0.03$ & $2.05 \pm 0.05$ & $2.59 \pm 0.09$ & $1.96 \pm 0.09$ & $2.33 \pm 0.33$ \\
No. of plots & & & & & \\
\hline
\end{tabular}

格局(Kallimanis et al, 2008)。

\section{2 负密度制约效应}

Janzen-Connel1假说认为, 专一性的病原菌能 够使同种个体之间的相互损害程度远大于种间个 体之间的损害，从而导致同种负密度制约(Janzen 1970; Connell 1971)。本研究通过比较不同生活史阶
段树木的多样性, 发现多样性指数随着径级的增加 呈现先高后低的趋势(表2)。这一格局与Webb等 (2006)研究婆罗洲热带雨林样地内不同径级个体谱 系多样性变化得出的结论一致, 表明负密度制约效 应主要作用于树木生活史早期, 通过增加同种幼苗 死亡率，降低同种幼苗密度，从而导致多样性指数 
表4 古田山24 ha森林样地幼苗与非幼苗生境的指示种

Table 4 The indicator species in seedling and non-seedling plots in the 24 ha GTS forest dynamics plot

\begin{tabular}{llll}
\hline 生境类型 & $1 \mathrm{~m} \times 1 \mathrm{~m}$ 幼苗样方 & $5 \mathrm{~m} \times 5 \mathrm{~m}$ 幼苗样方 & 24 ha样地(非幼苗样方) \\
Habitat type & $1 \mathrm{~m} \times 1 \mathrm{~m}$ seedling plots & $5 \mathrm{~m} \times 5 \mathrm{~m}$ seedling plots & 24 ha forest dynamics plot (non-seedling plots) \\
\hline 低地山谷 & 矩形叶鼠刺 Itea omeiensis & 虎皮楠 Daphniphyllum pentandrum & 浙江新木姜子 \\
Low valley & 杨梅叶蚊母树 Distylium myricoides & 矩形叶鼠刺 Itea omeiensis & 毛花连荵茶 Camellia fraterna \\
& 红楠 Machilus thunbergii & 拟赤杨 Alniphyllum fortunei & - \\
& - & 毛花连萝茶 Camellia fraterna & - \\
& - & 野漆树 Toxicodendron succedaneum & - \\
& - & 浙江新木姜子 & - \\
中位山坡 & 细叶青冈 Cyclobalanopsis gracilis & Neolitsea aurata var. chekiangensis & \\
Middle slope & 浙江红花油茶 Camellia chekiangoleosa & - \\
& 红楠 Machilus thunbergii & 灰白蜡瓣花 Corylopsis glandulifera & - \\
& - & 马银花 Rhododendron ovatum & - \\
高位山坡 & - & 北江芠花 Wikstroemia monnula & - \\
High slope & - & - & 短柄枹 Quercus serrata \\
& - & - & 毛果南烛 Lyonia ovalifolia var. hebecarpa \\
& - & - & 满山红 Rhododendron mariesii
\end{tabular}

随径级的增加而增加; 而在生活史晚期(成树阶段), 生境过滤起主导作用，更多稀有种个体被排除，从 而导致多样性指数下降。此外, $5 \mathrm{~m} \times 5 \mathrm{~m}$ 幼苗监测 样方与大样地非幼苗物种多度的关联分析发现：幼 苗与非幼苗个体物种多度间呈现异速增长关系，相 关系数远小于1 $(b=0.49 ; P<0.001)$, 说明同种或 亲缘关系较近并且处于同一样方内的幼苗, 更容易 受到病原菌的侵害或种内资源竞争的影响, 所以幼 苗死亡率较高(Comita et al, 2007; 王薇等, 2014)。可 见, 在幼苗更新的过程中, 负密度制约不仅是驱动 热带森林林下幼苗动态的关键因子, 在亚热带森林 中也发挥了重要作用(Harms et al, 2000)。

\section{3 幼苗监测样方稀有种分布}

在大型森林动态样地研究中, 1 ha面积内个体 数不多于 1 株的物种被定义为稀有种 (Hubbell \& Foster, 1986)。稀有种种群规模虽然较小, 受环境变 化影响较大, 在群落中的竞争力相对较弱, 但是在 某种程度上能起到平衡群落内部环境资源的重要 作用(Bachelot et al, 2013)。大量研究表明, 稀有种在
群落中所占比例极高, 占古田山样地中群落总物种 数的 $37.1 \%$ (祝燕等, 2008)、天童样地的 $36.20 \%$ (杨 庆松等, 2011)、八大公山样地的 $43.28 \%$ (卢志军等, 2013)以及鼎湖山样地的 $52.38 \%$ (叶万辉等, 2008)。 植物稀有性产生的原因多种多样，主要和物种本身 特性、分布范围、生境异质性、森林类型、区系的 交汇以及人为或自然干扰等相关(Bunyavejchewi et al, 2004; 叶万辉等, 2008)。但是基于大样地定义的 稀有种数量明显受到取样强度的影响, 由于大样地 仅对 $\mathrm{DBH} \geqslant 1 \mathrm{~cm}$ 的个体进行了监测, 很多物种在 DBH $<1 \mathrm{~cm}$ 阶段仍然存在大量个体, 基于 $\mathrm{DBH} \geqslant$ $1 \mathrm{~cm}$ 定义的稀有种在幼苗阶段可能并不稀有。我们 通过比较 $5 \mathrm{~m} \times 5 \mathrm{~m}$ 幼苗监测样方以及样地非幼苗 个体物种多度排序结果, 发现大样地内部分稀有种 (如山鸡椒、朱砂根、美丽胡枝子等)在幼苗监测样 方中分布较为广泛, 并非真正稀有(图4)。这可能和 不同物种生长发育特征密切相关, 例如部分小灌木 的胸径很少能超过 $1 \mathrm{~cm}$, 因此基于DBH $\geqslant 1 \mathrm{~cm}$ 个 体定义的稀有种可能并不准确, 群落内稀有种所占 
比例可能被高估。

\section{4 生境类型与指示种分布}

幼苗的定植与特定生境类型的选择作用密切 相关, 有些物种可以作为某些生境的指示种或代表 种(Cáceres et al, 2010)。5 m × $5 \mathrm{~m}$ 幼苗监测样方指示 种分析结果表明, 13种木本植物幼苗具有强烈的生 境特化倾向(表4)。低地山谷主要分布喜湿及喜阴的 物种, 例如矩形叶鼠刺(Itea omeiensis)、毛花连芯茶 (Camellia fraterna)、浙江新木姜子(Neolitsea aurata var. chekiangensis)。低地山脊在样地内的分布很广, 却没有明显的指示种, 很多物种都可以在低地山脊 生境中较好地生长。高地山脊水分资源相对较少, 环境胁迫较强, 广布着对干扰抵抗力较强的物种, 如木荷、美丽胡枝子、映山红(Rhododendron simsii) 等。该结果与Legendre等(2009)对 24 ha大样地内非 幼苗样方的生境指示种分析结果差异较大, 仅有 2 个物种(浙江新木姜子和毛花连芯茶)在幼苗阶段和 非幼苗阶段表征相同的生境关联。这可能是由于在 幼苗定植过程中, 受各种环境过滤的影响较大, 大 部分物种不容易成功定植所导致, 说明幼苗阶段的 生态位分化和生境偏好不同于非幼苗阶段, 这可能 与不同物种在不同发育阶段对环境的需求差异相 关(赖江山, 2008)。与 24 ha样地内 $1 \mathrm{~m} \times 1 \mathrm{~m}$ 幼苗样 方指示种(田锴等, 2013)相比, 仅在低地山谷和高地 山脊中有 3 个共同的指示种(矩形叶鼠刺、木荷、映 山红), 推测在取样面积差别比较大的情况下, 随着 取样面积的增大，某些物种对于某类生境的适合度 在逐渐增大, 而成为这类生境的特有指示种。由此 可见, 对幼苗样方进行扩建能够帮助我们更好地揭 示群落构建规律和多样性维持机制。

传统群落生态学对于幼苗的研究缺陷主要是 取样面积过小, 取样物种数过少等。通过大型固定 样地的建立以及其中 $5 \mathrm{~m} \times 5 \mathrm{~m}$ 幼苗监测样方的增 设, 可以更好地研究邻体效应或边缘效应对物种多 样性的影响, 更好地理解植物群落不同发育阶段生 物多样性的维持机制。在植物的整个生活史中, 幼 苗到幼树的阶段是群落中木本植物定植的瓶颈期, 是森林群落结构形成的关键时期。 $5 \mathrm{~m} \times 5 \mathrm{~m}$ 幼苗监 测样方的设置将有助于对幼苗与非幼苗阶段群落 特性与生物多样性维持过程进行更充分的比较, 这 将为验证和发展当今生态学理论中的一些重要问 题提供更好的平台。此外, 在调查的频次上, 每 2 年
一次的复查结果可进一步丰富野外监测数据, 在更 大的空间和时间尺度上研究物种分化和扩散机制, 为生物多样性维持机制的研究提供更加广阔的 思路。

致谢：感谢浙江省古田山国家级自然保护区管理局 对本项目给予的大力支持, 感谢为古田山 24 ha大 样地建设和调查付出艰辛努力的各位老师、同学和 工人师傅。

\section{参考文献}

Antos JA, Guest HJ, Parish R (2005) The tree seedling bank in an ancient montane forest: stress tolerators in a productive habitat. Journal of Ecology, 93, 536-543.

Bachelot B, Kobe RK, Vesk P (2013) Rare species advantage? Richness of damage types due to natural enemies increases with species abundance in a wet tropical forest. Journal of Ecology, 101, 846-856.

Bai XJ, Queenborough SA, Wang XG, Zhang J, Li BH, Yuan ZQ, Xing DL, Lin F, Ye J, Hao ZQ (2012) Effects of local biotic neighbors and habitat heterogeneity on tree and shrub seedling survival in an old-growth temperate forest. Oecologia, 170, 755-765.

Bin Y, Lin GJ, Li BH, Wu LF, Shen Y, Ye WH (2012) Seedling recruitment patterns in a 20 ha subtropical forest plot: hints for niche-based processes and negative density dependence. European Journal of Forest Research, 131, 453-461.

Bunyavejchewi S, Baker P, LaFrankie J, Ashton P (2004) Structure, history, and rarity in a seasonal evergreen forest in western Thailand. In: Forest Diversity and Dynamism: Findings from a Network of Large-scale Tropical Forest Plots (eds Losos EC, Leigh EG), pp. 145-158. University of Chicago Press, Chicago.

Cáceres MD, Legendre P, Moretti M (2010) Improving indicator species analysis by combining groups of sites. Oikos, 119, 1674-1684.

Carson WP, Jill TA, Egbert GL, Schnitzer SA (2008) Challenges associated with testing and falsifying the Janzen-Connell hypothesis: a review and critique. In: Tropical Forest Community Ecology (eds Carson WP, Schnitzer SA), pp. 210-241. Wiley-Blackwell Publishing, Chichester.

Chen GK, Kery M, Plattner M, Ma KP, Gardner B (2013) Imperfect detection is the rule rather than the exception in plant distribution studies. Journal of Ecology, 101, 183-191.

Chen L, Mi XC, Comita LS, Zhang LW, Ren HB, Ma KP (2010) Community-level consequences of density dependence and habitat association in a subtropical broad-leaved forest. Ecology Letters, 13, 695-704.

Chen ZH, Zhang DM, Lin FP (1996) Floristic and ecological studies of natural seedlings in the lower subtropical forest in 
Heishiding, Guangdong Province. Acta Phytoecologica Sinica, 20, 568-579. (in Chinese with English abstract) [陈 章和, 张德明, 林丰平 (1996) 广东黑石顶南亚热带森林 幼苗的区系和生态研究. 植物生态学报, 20, 568-579.]

Comita LS, Aguilar S, Pérez R, Lao S, Hubbell SP (2007) Patterns of woody plant species abundance and diversity in the seedling layer of a tropical forest. Journal of Vegetation Science, 18, 163-174.

Condit R (1998) Tropical Forest Census Plots: Methods and Results from Barro Colorado Island, Panama and a Comparison With Other Plots. Springer Science \& Business Media, Berlin.

Connell JH (1971) On the role of natural enemies in preventing competitive exclusion in some marine animals and in rain forest trees. In: Dynamics of Number in Populations (eds Boer PJ, Gradwell GR), pp. 298-310. Centre for Agricultural Publishing and Documentation, Wageningen, The Netherlands.

de Cáceres M, Legendre P (2009) Associations between species and groups of sites: indices and statistical inference. Ecology, 90, 3566-3574.

de Cáceres M, Legendre P, Moretti M (2010) Improving indicator species analysis by combining groups of sites. Oikos, $119,1674-1684$.

Dufrêne M, Legendre P (1997) Species assemblages and indicator species: the need for a flexible asymmetrical approach. Ecological Monographs, 67, 345-366.

Dungan JL, Perry JN, Dale MRT, Legendre P, Citraon-Pousty S, Fortin MJ, Jakomulska A, Miriti M, Rosenberg MS (2002) A balanced view of scale in spatial statistical analysis. Ecography, 25, 626-640.

Goldsmith GR, Comita LS, Morefield LL, Condit R, Hubbell SP (2006) Long-term research impacts on seedling community structure and composition in a permanent forest plot. Forest Ecology and Management, 234, 34-39.

Green PT, Harms KE, Connell JH (2014) Nonrandom, diversifying processes are disproportionately strong in the smallest size classes of a tropical forest. Proceedings of the National Academy of Sciences, USA, 111, 18649-18654.

Harms KE, Wright SJ, Calderón O, Hernández A, Herre EA (2000) Pervasive density-dependent recruitment enhances seedling diversity in a tropical forest. Nature, 404, 493-495.

Heck KL Jr, van Belle G, Simberloff D (1975) Explicit calculation of the rarefaction diversity measurement and the determination of sufficient sample size. Ecology, 56,1459-1461.

Hu ZH, Yu MJ, Ding BY, Fang T, Qian HY, Chen QC (2003) Types of evergreen broad-leaved forests and their species diversity in Gutian Mountain National Nature Reserve. Chinese Journal of Applied Environmental Biology, 9, 341-345. (in Chinese with English abstract) [胡正华, 于明 坚，丁炳扬，方腾，钱海源，陈启瑺 (2003) 古田山国家 级自然保护区常绿阔叶林类型及其群落物种多样性研究.
应用与环境生物学报, 9, 341-345.]

Hubbell SP, Foster RB (1986) Commonness and rarity in a neotropical forest: implications for tropical tree conservation. In: Conservation Biology: the Science of Scarcity and Diversity (ed. Soule ME), pp. 205-231. Sinauer Associates, Sunderland, Massachusetts.

Hubbell SP, Dallmeier F, Comiskey J (1998) The maintenance of diversity in a neotropical tree community: conceptual issues, current evidence, and challenges ahead. In: Forest Biodiversity Research, Monitoring and Modeling (eds Dallmeier F, Comiskey JA), pp. 17-44. UNESCO, Paris.

Hurlbert SH (1971) The nonconcept of species diversity: a critique and alternative parameters. Ecology, 52, 577-586.

Jansen PA, Visser MD, Joseph WS, Rutten G, Muller-Landau HC (2014) Negative density dependence of seed dispersal and seedling recruitment in a neotropical palm. Ecology Letters, 17, 11-20.

Janzen DH (1970) Herbivores and the number of tree species in tropical forests. The American Naturalist, 104, 501-528.

Jin Y, Chen JH, Mi XC, Ren HB, Ma KP, Yu MJ (2015) Impacts of the 2008 ice storm on structure and composition of an evergreen broad-leaved forest community in eastern China. Biodiversity Science, 23, 610-618. (in Chinese with English abstract) [金毅, 陈建华, 米湘成, 任海保, 马克 平, 于明坚 (2015) 古田山24 ha森林动态监测样地常绿 阔叶林群落结构和组成动态: 探讨2008年冰雪灾害的影 响. 生物多样性, 23, 610-618.]

Kallimanis AS, Mazaris AD, Tzanopoulos J, Halley JM, Pantis JD, Sgardelis SP (2008) How does habitat diversity affect the species-area relationship? Global Ecology and Biogeography, 17, 532-538.

Lai JS (2008) Species Habitat Associations and Species Coexistence on Evergreen Broadleaved Forest in Gutianshan, Zhejiang. PhD dissertation, Institute of Botany, Chinese Academy of Sciences, Beijing. (in Chinese with English abstract) [赖江山 (2008) 古田山常绿阔叶林物种生境关联 及其对物种共存的贡献. 博士学位论文, 中国科学院植 物研究所, 北京.]

Lambers JHR, Clark JS, Beckage B (2002) Density-dependent mortality and the latitudinal gradient in species diversity. Nature, 417, 732-735.

Lebrija-Trejos E, Pérez-García EA, Meave JA, Bongers F, Poorter L (2010) Functional traits and environmental filtering drive community assembly in a species-rich tropical system. Ecology, 91, 386-398.

Legendre P, Mi XC, Ren HB, Ma KP, Yu MJ, Sun YF, He FL (2009) Partitioning beta diversity in a subtropical broad-leaved forest of China. Ecology, 90, 663-674.

Li L, Chen JH, Ren HB, Mi XC, Yu MJ, Yang B (2010) Spatial patterns of Castanopsis eyrei and Schima superba in mid-subtropical broad-leaved evergreen forest in Gutian Mountain National Reserve, China. Chinese Journal of Plant 
Ecology, 34, 241-252. (in Chinese with English abstract) [李立，陈建华，任海保，米湘成，于明坚，杨波 (2010) 古田山常绿阔叶林优势树种甜槠和木荷的空间格局分析. 植物生态学报, 34, 241-252.]

Lin LX, Comita LS, Zheng Z, Cao M (2012) Seasonal differentiation in density-dependent seedling survival in a tropical rain forest. Journal of Ecology, 100, 905-914.

Lou LH, Jin SH (2000) Spermatophyta flora of Gutianshan Nature Reserve in Zhejiang. Journal of Beijing Forestry University, 22(5), 33-39. (in Chinese with English abstract) [楼炉焕, 金水虎 (2000) 浙江古田山自然保护区种子植 物区系分析. 北京林业大学学报, 22(5), 33-39.]

Lu ZJ, Bao DC, Guo YL, Lu JM, Wang QG, He D, Zhang KH, $\mathrm{Xu} Y Z$, Liu HB, Meng HJ, Huang HD, Wei XZ, Liao JX, Qiao XJ, Jiang MX, Gu ZR, Liao CL (2013) Community composition and structure of Badagongshan forest dynamic plot in a mid-subtropical mountain evergreen and deciduous broad-leaved mixed forest, central China. Chinese Journal of Plant Ecology, 31, 336-344. (in Chinese with English abstract) [卢志军, 鲍大川, 郭屹立, 路俊盟, 王庆刚, 何东, 张奎汉, 徐耀粘, 刘海波, 孟红杰, 黄汉东, 魏新增, 廖 建雄, 乔秀娟, 江明喜, 谷志容, 廖春林 (2013) 八大公 山中亚热带山地常绿落叶阔叶混交林物种组成与结构. 植物生态学报, 31, 336-344.]

McGill BJ, Enquist BJ, Weiher E, Westoby M (2006) Rebuilding community ecology from functional traits. Trends in Ecology and Evolution, 21, 178-185.

Mi XC, Swenson NG, Valencia R, Kress WJ, Erickson DL, Perez AJ, Ren HB, Su SH, Gunatilleke N, Gunatilleke S, Hao ZQ, Ye WH, Cao M, Suresh HS, Dattaraja HS, Sukumar R, Ma KP (2012) The contribution of rare species to community phylogenetic diversity across a global network of forest plots. The American Naturalist, 180, 17-30.

Muscarella R, Uriarte M, Forero-Montaña J, Comita LS, Swenson NG, Thompson J, Nytch CJ, Jonckheere I, Zimmerman JK,Zuidema P (2013) Life-history trade-offs during the seed-to-seedling transition in a subtropical wet forest community. Journal of Ecology, 101, 171-182.

Oksanen J, Blanchet FG, Kindt R, Legendre PR, O'Hara R, Simpson GL, Solymos P, Stevens MH, Wagner H (2013) Vegan: community ecology package. $\mathrm{R}$ package version 2.0-10. http://CRAN.R-project.org/package=vegan. (accessed on 2015-10-15)

Paine C, Norden N, Chave J, Forget PM, Fortunel C, Dexter KG, Baraloto C (2012) Phylogenetic density dependence and environmental filtering predict seedling mortality in a tropical forest. Ecology Letters, 15, 34-41.

Paine CT, Harms KE (2009) Quantifying the effects of seed arrival and environmental conditions on tropical seedling community structure. Oecologia, 160, 139-150.

Parent S, Simard MJ, Morin H, Messier C (2003) Establishment and dynamics of the balsam fir seedling bank in old forests of northeastern Quebec. Canadian Journal of Forest Research, 33, 597-603.

Pielou EC (1975) Ecological Diversity. Wiley, New York.

Shannon CE (1948) A mathematical theory of communication. Bell System Technical Journal, 27, 623-656.

Song YC, Yan ER, Song K (2015) Synthetic comparison of eight dynamics plots in evergreen broadleaf forests, China. Biodiversity Science, 23,139-148. (in Chinese with English abstract) [宋永昌, 阎恩荣, 宋坤 (2015) 中国常绿阔叶林 8 大动态监测样地植被的综合比较. 生物多样性, 23 , 139-148.]

Song YC, Chen XY, Wang XH (2005) Studies on evergreen broad-leaved froests of China: aretrospect and prospect. Journal of East China Normal University (Natural Science), (1), 1-8. (in Chinese with English abstract) [宋永昌, 陈小 勇, 王希华 (2005) 中国常绿阔叶林研究的回顾与展望. 华东师范大学学报(自然科学版), (1), 1-8.]

Svenning JC, Wright SJ (2005) Seed limitation in a Panamanian forest. Journal of Ecology, 93, 853-862.

Szwagrzyk J, Szewczyk J, Bodziarczyk J (2001) Dynamics of seedling banks in beech forest: results of a 10-year study on germination, growth and survival. Forest Ecology and Management, 141, 237-250.

Tian K, Chen L, Mi XC, Ma KP, Chen JH (2013) The effect of habitat filtering on tree seedling distribution in a subtropical evergreen broadleaf forest in China. Chinese Science Bulletin, 58, 3561-3569. (in Chinese with English abstract) [田 锴, 陈磊, 米湘成, 马克平, 陈建华 (2013) 亚热带常绿 阔叶林木本植物幼苗分布格局及其对生境过滤的响应. 科学通报, 58, 3561-3569.]

Ugland KI, Ellingsen KE (2003) The species-accumulation curve of estimation of species richness. Journal of Animal Ecology, 72, 888-897.

Wang XG, Wiegand T, Wolf A, Howe R, Davies SJ, Hao ZQ (2011) Spatial patterns of tree species richness in two temperate forests. Journal of Ecology, 99, 1382-1393.

Webb CO, Gilbert GS, Donoghue MJ (2006) Phylodiversity-dependent seedling mortality, size structure, and disease in a Bornean rain forest. Ecology, 87, 123-131.

Wu ZY (1980) Vegation of China. Science Press, Beijing. (in Chinese) [吴征镒 (1980) 中国植被. 科学出版社, 北京.]

Yang QS, Ma ZP, Xie YB, Zhang ZG, Wang ZH, Liu HM, Li P, Zhang N, Wang DL, Yang HB, Fang XF, Yan ER, Wang XH (2011) Community structure and species composition of an evergreen broadleaved forest in Tiantong's 20 ha dynamic plot, Zhejiang Province, eastern China. Biodiversity Science, 19, 215-223. (in Chinese with English abstract) [杨庆 松, 马遵平, 谢玉涁, 张志国, 王樟华, 刘何铭, 李萍, 张 娜, 王达力, 杨海波, 方晓峰, 间恩荣, 王希华 (2011) 浙 江天童 $20 \mathrm{ha}$ 常绿阔叶林动态监测样地的群落特征. 生 物多样性, 19, 215-223.] 
Ye WH, Cao HL, Huang ZL, Lian JY, Wang ZG, Li L, Wei SG, Wang ZM (2008) Community structure of a 20 ha lower subtropical evergreen broadleaved forest plot in Dinghushan, China. Journal of Plant Ecology (Chinese Version), 32, 274-286. (in Chinese with English abstract) [叶万 辉, 曹洪麟, 黄忠良, 练琚愉, 王志高, 李林, 魏识广, 王 章明 (2008) 鼎湖山南亚热带常绿阔叶林20公顷样地群 落特征研究. 植物生态学报, 32, 274-286.]

Zhu Y, Zhao GF, Zhang LW, Shen GC, Mi XC, Ren HB, Yu
MJ, Chen JH, Chen SW, Fang T, Ma KP (2008) Community composition and structure of Gutianshan forest dynamic plot in a mid-subtropical evergreen broad-leaved forest, East China. Journal of Plant Ecology (Chinese Version), 32, 262-273. (in Chinese with English abstract) [祝燕, 赵谷风, 张俪文, 沈国春, 米湘成, 任海保, 于明坚, 陈建华, 陈 声文, 方腾, 马克平 (2008) 古田山中亚热带常绿阔叶林 动态监测样地一群落组成与结构. 植物生态学报, 32 , 262-273.]

(责任编委: 王绪高 责任编辑: 黄祥忠)

\section{附录 Supplementary Material}

附录1 古田山 24 ha样地 $5 \mathrm{~m} \times 5 \mathrm{~m}$ 幼苗监测样方物种名录及个体数

Appendix 1 Species checklist and number of individuals of $5 \mathrm{~m} \times 5 \mathrm{~m}$ seedling plots in the 24 ha Gutianshan (GTS) forest dynamics plot

http://www.biodiversity-science.net/fileup/PDF/2015341-1.pdf 
郭印, 王云泉, 陈硈, 米湘成, 任海保, 陈声文, 陈建华. 不同取样强度下古田山木本植物幼苗组成及其分布格局比较. 生物 多样性, 2016, 24 (10): 1093-1104.

http://www.biodiversity-science.net/CN/10.17520/biods.2015341

附表1 古田山 24 ha样地 $5 \mathrm{~m} \times 5$ m幼苗监测样方物种名录及个体数

Appendix 1 Species checklist and number of individuals of $5 \mathrm{~m} \times 5 \mathrm{~m}$ seedling plots in the 24 ha Gutianshan (GTS) forest dynamics plot

\begin{tabular}{|c|c|c|c|c|}
\hline $\begin{array}{l}\text { 物种 } \\
\text { Species }\end{array}$ & $\begin{array}{l}\text { 拉丁种名 } \\
\text { Scientific name }\end{array}$ & $\begin{array}{l}\text { 中文科名 } \\
\text { Chinese family name }\end{array}$ & $\begin{array}{l}\text { 拉丁科名 } \\
\text { Family name }\end{array}$ & $\begin{array}{l}\text { 个体数 } \\
\text { No of individuals }\end{array}$ \\
\hline $\begin{array}{l}\text { 甜槠 } \\
\end{array}$ & Castanopsis eyrei & 壳斗科 & Fagaceae & 4110 \\
\hline 拟赤杨 & Alniphyllum fortunei & 安息香科 & Styracaceae & 1448 \\
\hline 虎皮楠 & Daphniphyllum oldhamii & 虎皮楠科 & Daphniphyllaceae & 949 \\
\hline 赤楠 & Syzygium buxifolirm & 桃金娘科 & Myrtaceae & 900 \\
\hline 浙江新木姜子 & Neolitsea aurata var. chekiangensis & 樟科 & Lauraceae & 791 \\
\hline 浙江红花油茶 & Camellia chekiangoleosa & 山茶科 & Theaceae & 783 \\
\hline 柳叶蜡梅 & Chimonanthus salicifolius & 蜡梅科 & Calycanthaceae & 688 \\
\hline 杨梅叶蚊母树 & Distylium myricoides & 金缕梅科 & Hamamelidaceae & 627 \\
\hline 隔药柃 & Eurya muricata & 山茶科 & Theaceae & 625 \\
\hline 矩形叶鼠刺 & Itea chinensis & 虎耳草科 & Saxifragaceae & 583 \\
\hline 木荷 & Schima superba & 山茶科 & Theaceae & 545 \\
\hline 毛花连荵茶 & Camellia fraterna & 山茶科 & Theaceae & 536 \\
\hline 石斑木 & Raphiolepis indica & 菩薇科 & Rosaceae & 434 \\
\hline 马银花 & Rhododendron ovatum & 杜鹃花科 & Ericaceae & 428 \\
\hline 厚皮香 & Ternstroemia gymnanthera & 山茶科 & Theaceae & 323 \\
\hline 细叶青冈 & Cyclobalanopsis gracilis & 壳斗科 & Fagaceae & 315 \\
\hline 灰白蜡瓣花 & Corylopsis glandulifera & 金缕梅科 & Hamamelidaceae & 311 \\
\hline 山鸡椒 & Litsea cubeba & 樟科 & Lauraceae & 296 \\
\hline 红楠 & Machilus thunbergii & 樟科 & Lauraceae & 293 \\
\hline 栲树 & Castanopsis fargesii & 壳斗科 & Fagaceae & 273 \\
\hline 野漆树 & Toxicodendron succedaneum & 漆树科 & Anacardiaceae & 270 \\
\hline 青冈 & Cyclobalanopsis glauca & 壳斗科 & Fagaceae & 267 \\
\hline 朱砂根 & Ardisia crenata & 紫金牛科 & Myrsinaceae & 253 \\
\hline 聯木 & Loropetalum chinensis & 金缕梅科 & Hamamelidaceae & 235 \\
\hline 红枝柴 & Meliosma oldhamii & 清风藤科 & Sabiaceae & 171 \\
\hline 白花苦灯笼 & Tarenna mollissima & 茜草科 & Rubiaceae & 168 \\
\hline 小果冬青 & Ilex micrococca & 冬青科 & Aquifoliaceae & 158 \\
\hline 鹿角杜鹃 & Rhododendron latoucheae & 杜鹃花科 & Ericaceae & 151 \\
\hline 石栎 & Lithocarpus glaber & 壳斗科 & Fagaceae & 146 \\
\hline 马尾松 & Pinus massoniana & 松科 & Pinaceae & 136 \\
\hline 乳源木莲 & Manglietia yuyuanensis & 木兰科 & Magnoliaceae & 135 \\
\hline 郁香野茉莉 & Styrax odoratissimus & 安息香科 & Styracaceae & 128 \\
\hline 花椒勒 & Zanthoxylum scandens & 芸香科 & Rutaceae & 126 \\
\hline 浙江柿 & Diospyros glaucifolia & 柿科 & Ebenaceae & 121 \\
\hline 山桐子 & Idesia polycarpa & 大风子科 & Flacourtiaceae & 105 \\
\hline 美丽胡枝子 & Lespedeza formosa & 豆科 & Leguminosae & 105 \\
\hline 乌饭 & Vaccinium bracteatum & 杜鹃花科 & Ericaceae & 100 \\
\hline 垂珠花 & Styrax dasyanthus & 安息香科 & Styracaceae & 99 \\
\hline 老鼠矢 & Symplocos stellaris & 山矾科 & Symplocaceae & 94 \\
\hline 江南越桔 & Vaccinium mandarinorum & 杜鹃花科 & Ericaceae & 90 \\
\hline 黄瑞木 & Adinandra millettii & 山茶科 & Theaceae & 90 \\
\hline 臭辣树 & Euodia fargesii & 芸香科 & Rutaceae & 83 \\
\hline
\end{tabular}




\begin{tabular}{|c|c|c|c|c|}
\hline $\begin{array}{l}\text { 物种 } \\
\text { Species }\end{array}$ & $\begin{array}{l}\text { 拉丁种名 } \\
\text { Scientific name }\end{array}$ & $\begin{array}{l}\text { 中文科名 } \\
\text { Chinese family name }\end{array}$ & $\begin{array}{l}\text { 拉丁科名 } \\
\text { Family name }\end{array}$ & $\begin{array}{l}\text { 个体数 } \\
\text { No. of individuals }\end{array}$ \\
\hline 杜英 & Elaeocarpus decipiens & 杜英科 & Elaeocarpaceae & 80 \\
\hline 映山红 & Rhododendron simsii & 杜鹃花科 & Ericaceae & 78 \\
\hline 光叶石楠 & Photinia glabra & 蓄薇科 & Rosaceae & 72 \\
\hline 北江荛花 & Wikstroemia monnula & 瑞香科 & Thymelaeaceae & 70 \\
\hline 杨梅 & Myrica rubra & 杨梅科 & Myricaceae & 70 \\
\hline 大青 & Clerodendrum cyrtophyllum & 马鞭草科 & Verbenaceae & 66 \\
\hline 狗骨柴 & Diplospora dubia & 茜草科 & Rubiaceae & 65 \\
\hline 南酸崽 & Choerospondias axiliaris & 漆树科 & Anacardiaceae & 64 \\
\hline 豹皮樟 & Litsea coreana var.sinensis & 樟科 & Lauraceae & 60 \\
\hline 短柄枹 & Quercus serrata & 壳斗科 & Fagaceae & 58 \\
\hline 栃子 & Gardenia jasminoides & 茜草科 & Rubiaceae & 57 \\
\hline 细叶香桂 & Cinnamomum subavenium & 樟科 & Lauraceae & 56 \\
\hline 窄基红褐柃 & Eurya rubiginosa var. attenuata & 山茶科 & Theaceae & 55 \\
\hline 海南槽裂木 & Pertusadina hainanensis & 茜草科 & Rubiaceae & 50 \\
\hline 美丽马醉木 & Pieris formosa & 杜鹃花科 & Ericaceae & 48 \\
\hline 山合欢 & Albizia kalkora & 豆科 & Leguminosae & 48 \\
\hline 短尾越桔 & Vaccinium carlesii & 杜鹃花科 & Ericaceae & 46 \\
\hline 山橿 & Lindera reflexa & 樟科 & Lauraceae & 46 \\
\hline 白背麸杨 & Rhus hypoleuca & 漆树科 & Anacardiaceae & 45 \\
\hline 野鸦椿 & Euscaphis japonica & 省沽油科 & Staphyleaceae & 42 \\
\hline 掌叶覆盆子 & Rubus chingii & 蓄薇科 & Rosaceae & 41 \\
\hline 红紫珠 & Callicarpa rubella & 马鞭草科 & Verbenaceae & 38 \\
\hline 冬青 & Ilex chinensis & 冬青科 & Aquifoliaceae & 37 \\
\hline 黄檀 & Dalbergia hupeana & 豆科 & Leguminosae & 37 \\
\hline 刺叶桂樱 & Prunus spinulosa & 蓄薇科 & Rosaceae & 37 \\
\hline 中国绣球 & Hydrangea chinensis & 虎耳草科 & Saxifragaceae & 33 \\
\hline 矮茎紫金牛 & Ardisia brevicaulis & 紫金牛科 & Myrsinaceae & 32 \\
\hline 厚叶冬青 & Ilex elmerrilliana & 冬青科 & Aquifoliaceae & 31 \\
\hline 虎刺 & Damnacanthus indicus & 茜草科 & Rubiaceae & 28 \\
\hline 榕叶冬青 & Ilex ficoidea & 冬青科 & Aquifoliaceae & 27 \\
\hline 薯豆 & Elaeocarpus japonicus & 杜英科 & Elaeocarpaceae & 26 \\
\hline 苦枥木 & Fraxinus insularis & 木犀科 & Oleaceae & 26 \\
\hline 宜昌荚蒾 & Viburnum erosum & 忍冬科 & Caprifoliaceae & 25 \\
\hline 毛八角枫 & Alangium kurzii & 八角枫科 & Alangiaceae & 24 \\
\hline 野含笑 & Michelia skinneriana & 木兰科 & Magnoliaceae & 24 \\
\hline 紫果槭 & Acer cordatum & 槭树科 & Aceraceae & 23 \\
\hline 小叶青冈 & Cyclobalanopsis myrsinifolia & 壳斗科 & Fagaceae & 23 \\
\hline 岭南花椒 & Zanthoxylum austrosinense & 芸香科 & Rutaceae & 21 \\
\hline 白背叶 & Mallotus apelta & 大戟科 & Euphorbiaceae & 20 \\
\hline 红淡比 & Cleyera japonica & 山茶科 & Theaceae & 20 \\
\hline 紫珠 & Callicarpa bodinieri & 马鞭草科 & Verbenaceae & 20 \\
\hline 尖连莣茶 & Camellia cuspidata & 山茶科 & Theaceae & 16 \\
\hline 豆腐柴 & Premna microphylla & 马鞭草科 & Verbenaceae & 16 \\
\hline 黄线润楠 & Machilus grijsii & 樟科 & Lauraceae & 15 \\
\hline 醉鱼草 & Buddleja lindleyana & 马钱科 & Loganiaceae & 15 \\
\hline 海州常山 & Clerodendrum trichotomum & 马鞭草科 & Verbenaceae & 15 \\
\hline 大叶白纸扇 & Mussaenda shikokiana & 茜草科 & Rubiaceae & 13 \\
\hline 黄丹木姜子 & Litsea elongata & 樟科 & Lauraceae & 12 \\
\hline 小构树 & Broussonetia kazinoki & 桑科 & Moraceae & 12 \\
\hline 大叶冬青 & Ilex latifolia & 冬青科 & Aquifoliaceae & 11 \\
\hline
\end{tabular}




\begin{tabular}{|c|c|c|c|c|}
\hline $\begin{array}{l}\text { 物种 } \\
\text { Species }\end{array}$ & $\begin{array}{l}\text { 拉丁种名 } \\
\text { Scientific name }\end{array}$ & $\begin{array}{l}\text { 中文科名 } \\
\text { Chinese family name }\end{array}$ & $\begin{array}{l}\text { 拉丁科名 } \\
\text { Family name }\end{array}$ & $\begin{array}{l}\text { 个体数 } \\
\text { No. of individuals }\end{array}$ \\
\hline 小槐花 & Ohwia caudata & 豆科 & Leguminosae & 11 \\
\hline 罗浮柿 & Diospyros morrisina & 柿科 & Ebenaceae & 10 \\
\hline 钩栲 & Castanopsis tibetana & 壳斗科 & Fagaceae & 10 \\
\hline 光萝林檎 & Malus leiocalyca & 蔷薇科 & Rosaceae & 10 \\
\hline 毛冬青 & Ilex pubescens & 冬青科 & Aquifoliaceae & 9 \\
\hline 淴木 & Aralia chinensis & 五加科 & Araliaceae & 9 \\
\hline 铁冬青 & Ilex rotunda & 冬青科 & Aquifoliaceae & 8 \\
\hline 猴欢喜 & Sloanea sinensis & 杜英科 & Elaeocarpaceae & 8 \\
\hline 浙江樟 & Cinnamomum chekiangense & 樟科 & Lauraceae & 8 \\
\hline 海金子 & Pittosporum illicioides & 海桐花科 & Pittosporaceae & 8 \\
\hline 山矾 & Symplocos sumuntia & 山矾科 & Symplocaceae & 8 \\
\hline 薄叶山矾 & Symplocos anomala & 山矾科 & Symplocaceae & 7 \\
\hline 黄果朴 & Celtis biondii & 榆科 & Ulmaceae & 7 \\
\hline 米槠 & Castanopsis carlesii & 壳斗科 & Fagaceae & 6 \\
\hline 檫木 & Sassafras tzumu & 樟科 & Lauraceae & 5 \\
\hline 宁波木犀 & Osmanthus cooperi & 木犀科 & Oleaceae & 5 \\
\hline 矩叶卫矛 & Euonymus oblongifolius & 卫矛科 & Celastraceae & 4 \\
\hline 木油桐 & Vernicia montana & 大戟科 & Euphorbiaceae & 4 \\
\hline 创花楠 & Machilus pauhoi & 樟科 & Lauraceae & 4 \\
\hline 浙闽樱 & Cerasus schneideriana & 蓄薇科 & Rosaceae & 4 \\
\hline 华杜英 & Elaeocarpus chinensis & 杜英科 & Elaeocarpaceae & 3 \\
\hline 满山红 & Rhododendron mariesii & 杜鹃花科 & Ericaceae & 3 \\
\hline 算盘子 & Glochidion puberum & 大戟科 & Euphorbiaceae & 3 \\
\hline 青灰叶下珠 & Phyllanthus glaucus & 大戟科 & Euphorbiaceae & 3 \\
\hline 酸味子 & Antidesma japonicum & 大戟科 & Euphorbiaceae & 3 \\
\hline 光叶毛果枳椇 & Hovenia trichocarpa var. robusta & 鼠李科 & Rhamnaceae & 3 \\
\hline 石灰花楸 & Sorbus folgneri & 菩薇科 & Rosaceae & 3 \\
\hline 石楠 & Photinia serrulata & 菩薇科 & Rosaceae & 3 \\
\hline 鸡仔木 & Sinoadina racemosa & 茜草科 & Rubiaceae & 3 \\
\hline 山油麻 & Trema cannabina var. dielsiana & 榆科 & Ulmaceae & 3 \\
\hline 木姜叶冬青 & Ilex litseifolia & 冬青科 & Aquifoliaceae & 2 \\
\hline 香冬青 & Ilex suaveolens & 冬青科 & Aquifoliaceae & 2 \\
\hline 毛果南烛 & Lyonia ovalifolia & 杜鹃花科 & Ericaceae & 2 \\
\hline 黄山木兰 & Yulania cylindrica & 木兰科 & Magnoliaceae & 2 \\
\hline 杜茎山 & Maesa japonica & 紫金牛科 & Myrsinaceae & 2 \\
\hline 日本粗叶木 & Lasianthus japonicus subsp. japonicus & 茜草科 & Rubiaceae & 2 \\
\hline 老鸦糊 & Callicarpa giraldii & 马鞭草科 & Verbenaceae & 2 \\
\hline 盐肤木 & Rhus chinensis & 漆树科 & Anacardiaceae & 1 \\
\hline 尾叶冬青 & Ilex wilsonii & 冬青科 & Aquifoliaceae & 1 \\
\hline 水马桑 & Weigela japonica & 忍冬科 & Caprifoliaceae & 1 \\
\hline 中华石楠 & Photinia beauverdiana & 菩薇科 & Rosaceae & 1 \\
\hline 山黄皮 & Aidia cochinchinensis & 茜草科 & Rubiaceae & 1 \\
\hline 垂枝泡花树 & Meliosma flexuosa & 清风藤科 & Sabiaceae & 1 \\
\hline 中国権节花 & Stachyurus chinensis & 㫌节花科 & Stachyuraceae & 1 \\
\hline 密花梭罗树 & Reevesia pycnantha & 梧桐科 & Sterculiaceae & 1 \\
\hline 浆果椴 & Tilia endochrysea & 椴树科 & Tiliaceae & 1 \\
\hline
\end{tabular}

